\title{
MOTOR SKILLS OF YOUNG ADULTS WITH ASPERGER SYNDROME: A COMPARATIVE STUDY
}

\author{
Erwin Borremans \\ Keskuspuisto Vocational Institute, Helsinki, Finland. \\ Pauli Rintala \\ University of Jyväskylä, Jyväskylä, Finland. \\ Jeffrey A. McCubbin \\ Oregon State University, Corvallis, Oregon, U.S.A.
}

\begin{abstract}
Motor skill difficulties are mentioned as a common feature of Asperger syndrome (AS) but specific information regarding young adults is scarce. The purposes of this study were: to compare the motor skills of young adults with AS with age and gender matched controls using the updated version of the standardized Movement Assessment battery for children (M-ABC-II), and to compare the motor skills between younger and older participants within both groups (index and control group). Additionally validity and reliability of the M-ABC-II for use with the present population were explored. Young adults with AS performed these motor tasks at a remarkably lower level than their peers. They continued to demonstrate motor delays over age, even though motor competencies of individuals with AS seemed to improve after the adolescent years. The use of the M-ABC-II is recommended for young adults with AS as a valuable tool in assessing motor skills for setting up the intervention in educational and clinical practice.
\end{abstract}

KEYWORDS: Asperger syndrome, motor skills, motor competence, clumsiness, M-ABC-II, adults.

\section{INTRODUCTION}

Asperger syndrome (AS) is a neurodevelopmental disorder grouped under the broad diagnostic category of pervasive developmental disorders (PDD), also referred to as Autism Spectrum Disorders (ASD). It is characterized by the same kind of qualitative abnormalities of social interaction that typify autism, together with a restricted, stereotyped, repetitive repertoire of interests and activities. AS is considered to be at the higher end of the continuum of the autism spectrum and it differs from autism primarily in the absence of general delay or retardation in language or in cognitive development. Most individuals are of normal intelligence and it is common for them to be markedly clumsy (World Health Organisation, 1993).

The number of individuals with AS increased dramatically over the last decade, although its exact prevalence has yet to be determined. Recent research in Finland suggests that it may be as common as one in
250 people $(0.4 \%)$ (Mattila et al., 2007). This number is in line with international resources, which have shown prevalence rates between one in $150(0.6 \%)$ and one in 500 people (0.2\%) (Baird et al., 2006; Fombonne, 2003; Posserud, Lundervold, \& Gillberg, 2006). Epidemiological evidence indicates that the male/female ratio is 4:1 (Ehlers, Gillberg, \& Wing, 1999), but recent research suggests that this female prevalence may be underestimated and that the male/female ratio could be up to 2:1 (Mattila et al., 2007).

Motor clumsiness is mentioned as a common, yet not defining, feature of Asperger syndrome in both the ICD-10 (World Health Organisation, 1993) and the DSM-IV (American Psychiatric Association, 1994). Estimates of the prevalence of these motor problems range from $50 \%$ to $85 \%$ (Attwood, 1998; Gillberg \& Gillberg, 1989; Klin, Volkmar, Sparrow, Cicchetti, \& Rourke, 1995; Manjiviona \& Prior, 1995; Sahlander, Mattsson, \& Bejerot, 2008; Smith, 2000), but 
the specific characteristics of the impairment remain poorly understood. These motor problems can involve different domains, including fine motor and gross motor skills, gait, balance, and ball skills. Individuals with AS may have a history of delayed acquisition of specific motor skills such as walking, pedaling a bike, catching a ball, standing on one leg, hopping, climbing parallel-bars, and so on. They are often visibly awkward, exhibiting stiff gait patterns, odd posture, poor manipulative skills, and deficits in visual-motor coordination. The pervasive nature of these motor problems, as well as the fact that more children are being diagnosed every year due to a greater awareness of $\mathrm{AS}$, makes it increasingly likely that physical education teachers and coaches will have children with AS in their programs and on their teams.

Often the presence of clumsiness in AS has been defined on the basis of the clinician's subjective impression and only a limited number of studies have used standardized tests of motor skill, such as Bruininks-Oseretsky test of Motor Proficiency (BOTMP; Bruininks, 1976), Movement Assessment battery for Children (M-ABC; Henderson \& Sudgen, 1992), and Zuricher Neuromotor assessment (Largo, Fischer, \& Caflisch, 2002). Despite of the wide variety of test used, there seems to be agreement that motor impairment is very common among children and adolescents with $\mathrm{AS}$ and autism.

The M-ABC or its precursor the Test of Motor Impairment-Henderson Revision have been used in several studies on children with AS or high functioning autism (HFA)(Green et al., 2002; Manjiviona \& Prior, 1995; Miyahara et al., 1997). The M-ABC is a quantitative, norm-referenced instrument for 4-12 year old children assessing manual dexterity, ball skills and balance. Manjiviona \& Prior (1995) compared 21 children and adolescents between 7-17 years old with AS and HFA and did not find differences between the groups regarding the three components and the overall test scores. They reported considerable variability within both clinical groups with $50 \%$ of the children with AS and $67 \%$ of children with HFA showing a clinically significant level of motor impairment. Others using the $\mathrm{M}-\mathrm{ABC}$ with children with AS as compared to other special groups (Green et al., 2002; Miyahara et al., 1997) reported similar results with 88 to $100 \%$ of the children with AS meeting the diagnosis for motor impairment.

Motor impairment has been well documented in children, whereas specific information regarding young adults remains scarce. Recently Sahlander and colleagues (Sahlander et al., 2008) used the BOTMP in a comparative study of motor function in adults with AS aged 21-35. This study indicated similar motor difficulties in adults as were also shown in children in previous research using the BOTMP (Ghaziuddin \& Butler, 1998; Ghaziuddin, Butler, Tsai, \& Ghaziuddin, 1994; Lopata, Hamm, Volker, \& Sowinski, 2007; Sahlander et al., 2008). Freitag and colleagues (2007) compared 16 male young adults aged 14-22 years with healthy controls using the Zurich Neuromotor Assessment. Their index group had the most difficulties with dynamic balance skills and the ability to perform rapidly alternating muscular movements. Both these studies made use of a rather small number of index participants with matched controls and population specific reliability data was not provided. Because of the unavailability of normative standardized motor tests for young adults with AS information regarding this specific age group from 15 till 21 is limited. Therefore, the primary purpose of this study was to compare both quantitatively and qualitatively the motor skills of young adults with AS with age and gender matched controls. Secondly, this study compared motor skills between younger and older participants of both index and control groups. Additionally internal consistency reliability of the M-ABC-II for young adults with AS was explored.

\section{METHOD}

\section{Participants}

Thirty young adults aged $15-21$ years $(\mathrm{M}=$ 17.2yrs; SD $=1.2$ ) with Asperger syndrome agreed to participate in the study. Members of the group with AS were selected from a vocational education program, especially designed for young adults with ASD, in the 
province of southern Finland. To be included in this group, all participants were required to meet the diagnostic criteria for AS as presented in the ICD-10R (WHO, 1993) (i.e. qualitative deficiencies in reciprocal social interaction, and restricted, repetitive stereotyped patterns of behavior, interest and activities, but no clinically significant delay in language or cognitive development). A professional who had considerable experience diagnosing people on the autism spectrum made the diagnosis. Mental retardation and psychosis were used as exclusion criteria. The group enrolled consisted of 21 males $(M=16.9 \mathrm{yrs} ; \mathrm{SD}=0.9 \mathrm{yrs})$ and 9 females $(\mathrm{M}=18.0 \mathrm{yrs} ; \mathrm{SD}=1.4 \mathrm{yrs})$. This gender disbalance is in line with the most recent epidemiological data (Ehlers, et al., 1999; Mattila, et al., 2007). Prior to all investigations, written assent was obtained from the participants and written consent from their legal guardians. The control group consisted of 30, age and gender matched, young adults $(\mathrm{M}=16.9$; $\mathrm{SD}=0.8 \mathrm{yrs})$ from an upper secondary school in the same region. They had no physical or cognitive impairments according to their own reports. The appropriate ethical committee approved this study.

\section{Assessment}

The updated version of the Movement Assessment Battery for Children, the M-ABCII, was used as the primary assessment tool (Henderson, Sugden, \& Barnett, 2007). The MABC-II test is divided into three age bands with movement tasks getting more difficult with increasing age. The M-ABC-II test contains eight tasks that assess three components of functioning: manual dexterity, balance and ball skills. The manual dexterity tasks include turning pegs both with preferred and non-preferred hand, a bimanual task to make a triangle with nuts and bolts, and a drawing trail. The tests for ball skills include aiming and throwing at a wall target, as well as catching a ball with one hand. Balance items consist of two-board balance, walking toe-toheel backwards, and zigzag hopping.

The test provides objective, quantitative data on motor skills. The raw scores obtained for each item can be converted to item standard scores using age related norms. Performance differences between boys and girls are reported to be minimal, so the M-ABC-II manual provides only a single set of norms. Standard scores can be added up to produce three component scores, the sum of which provides a total test score. The test provides standard scores and percentiles for each age group through 16. According to the M-ABC-II manual scores at or below the $5^{\text {th }}$ percentile are considered indicative of significant motor difficulty and scores between the $6^{\text {th }}$ and $15^{\text {th }}$ percentile suggest being at risk for having motor problems. In addition to the quantitative data derived from formal testing, the assessment is also paralleled by item-specific observations, designed to increase understanding of the perceptual-motor aspects of the individual's performance. Both quantitative data as well as qualitative clinical impressions, are included in this study to help describe and characterize some specific motor related challenges of individuals with AS.

To our knowledge currently there is no specific norm referenced motor skill test available for this age range, which includes ball skills, as well as both fine and gross motor abilities. We opted for the M-ABC-II as different versions of this test have been commonly used in motor competence research with individuals with AS (Green et al., 2002; Manjiviona \& Prior, 1995; Miyahara et al., 1997; Siaperas, Holland, \& Ring, 2006) and its careful use offers trained professionals valuable clinical information to plan an intervention. The M-ABC-II test has proven reliable and valid (Chow \& Henderson, 2003; Faber \& Nijhuis van der Sanden, 2004; Henderson, et al., 2007). In our view the test has sensitivity for our group of young adults with AS because their motor skills have not yet reached optimal levels and variability is still to be observed. Therefore we were interested in the suitability of the M-ABC-II test for individuals older than 16 , even though 16 is the upper age limit of the normative sample. To confirm internal consistency reliability our statistical analyses included Crohnbach's Alpha.

\section{Procedures}

A team of three experienced therapists (two physiotherapists and one occupational 
therapist) assessed the individuals with and without AS between September 2007 and February 2008. In a quiet classroom, each assessment was initiated with a short interview and an informative briefing about the test situation supported with pictures of the test items. After that, the manual dexterity and balance tests were administered. In total, this first session took approximately half an hour. Ball skills were assessed as a part of a larger physical fitness assessment during the student's regular physical education in the school's gymnasium. These different fitness- and motor tests were conducted in small groups from two to four persons. The student-teacher ratio was 2:1.

\section{Data analysis}

Of all our 60 participants, 40 were older than 16. Therefore, the statistical analysis was performed on the raw scores due to lack of normative information for adults. A 5\% level of statistical significance is being implied (.05). First, the items were combined in a MANOVA-model using summation of all raw scores to reflect the total test score as well as combinations of raw scores to reflect the component scores of the M-ABC-II. The hypothesis was that the group with AS would score significantly lower than the control group on overall motor ability as well as on the three components. In an additional analysis using the same MANOVA-model as described above, gender was used as a covariate to address for possible gender differences. For descriptive reasons and to be able to indicate the severity of the motor impairment in our index group we decided to do a confirmatory calculation of standard scores and percentiles using the norms of the 16 year olds from the M-ABC-II manual. Using these norms with a slightly older population would likely underestimate the individuals' motor competencies, because it does not account for higher scores that come with increasing age.

Second, both the index group and the control group were split in half, using age as the criterion, to get a younger and an older group. This younger group (with the fifteen youngest) was compared to the older group (with the fifteen oldest) within both index and control group. A similar MANOVA using summation of raw scores to reflect motor competence was applied. The hypothesis was that in the control group, the scores of the oldest are similar to the scores of the youngest, since motor development is supposed to have consolidated before reaching adulthood. On the other hand, the hypothesis with the group with AS was that there would be a difference on the scores in favor of the older group. This hypothesis was based upon the lower initial score of the group with AS that suggests a possible margin for growth. Effect sizes based on means (Cohen's d; Cohen, 1988) were calculated for the individual test items to help us to know whether the differences observed between the groups are differences that practically matter.

The third goal was to provide exploratory information for further development and normation of future measurements for young adults with AS. The M-ABC-II's underlying construction allows for an analysis of the items for internal consistency reliability. We used the Cronbach's alpha to measure how well the set of items per component in the M-ABC-II measure the proposed latent construct and as an indicator of reliability of this test for our age specific group. Given the nature of the test and the small sample size, we do want to stress that it is merely an indicator.

\section{RESULTS}

The means and standard deviations of the M-ABC-II raw test score of both groups are summarized in Table 1. First, the multivariate analysis of variance revealed statistically significant lower motor performance of the index group compared to control group on overall motor competence (Wilk's Lambda $\lambda=$ $.49, F(11,48)=4.48(\mathrm{p}<.001)$ as well as on all three motor components (manual dexterity, ball skills, and balance) of the M-ABC-II. Wilk's Lambda for manual dexterity items was $\lambda=.72, F(4,55)=5.29(\mathrm{p}<.001)$; for ball skill items $\lambda=.63, F(3,56)=11.06(\mathrm{p}<.001)$; and for balance items $\lambda=.65, F(4,55)=7.34(\mathrm{p}<$ $.001)$. The additional MANCOVA showed as expected no significant gender differences with Wilk's Lambda $\lambda=.80, F(11,47)=1.09$, and 
$\mathrm{p}>.05$. The confirmatory calculation of standard scores and percentiles indicated the severity of the motor impairment in the group with AS (see Figure 1). According to the cutoff scores proposed in the M-ABC-II manual our results suggest that of the 30 participants in the group with AS 17 had severe motor problems (scored below $5^{\text {th }}$ percentile) and an additional two would be at risk for motor impairment (scored between the $5^{\text {th }}$ and $15^{\text {th }}$ percentile) (see Figure 2).

\section{Table 1}

Group means (SD) for manual dexterity, ball skill, and balance tasks of M-ABC-II

Group with AS

$(\mathrm{N}=30)$
Control group

$(\mathrm{N}=30)$

\section{Manual dexterity}

Peg turning

Preferred hand (time, $s$ )

Non-preferred hand (time, $s$ )

Triangle with bolt \& nuts (s)

Drawing trail (\#/errors)

\section{Ball skills}

Catching

Preferred hand (\#catches/10)

Non-preferred hand (\#catches/10)

Throw at target (\#hits/10)

\section{Balance}

Two board balance (s)

Toe-to-heel (\#/steps)

Zigzag hopping

Best leg (\#/hops)

Other leg (\#/hops)

$$
\begin{gathered}
21.80 \pm 5.22(15-46) \\
24.60 \pm 9.12(17-40) \\
63.40 \pm 34.20(25-255) \\
1.00 \pm 1.95(0-8)
\end{gathered}
$$$$
19.77 \pm 2.75(15-26)
$$$$
37.60 \pm 7.90(27-47)
$$$$
0.40 \pm 1.04(0-5)
$$

Note. Mean \pm Standard Deviations, values enclosed in parentheses represent range of scores. 
Figure 1. Mean component - and total test scores (+SD) of the M-ABC-II for both group with AS $(\mathrm{N}=30)$ and control group $(\mathrm{N}=30)$.

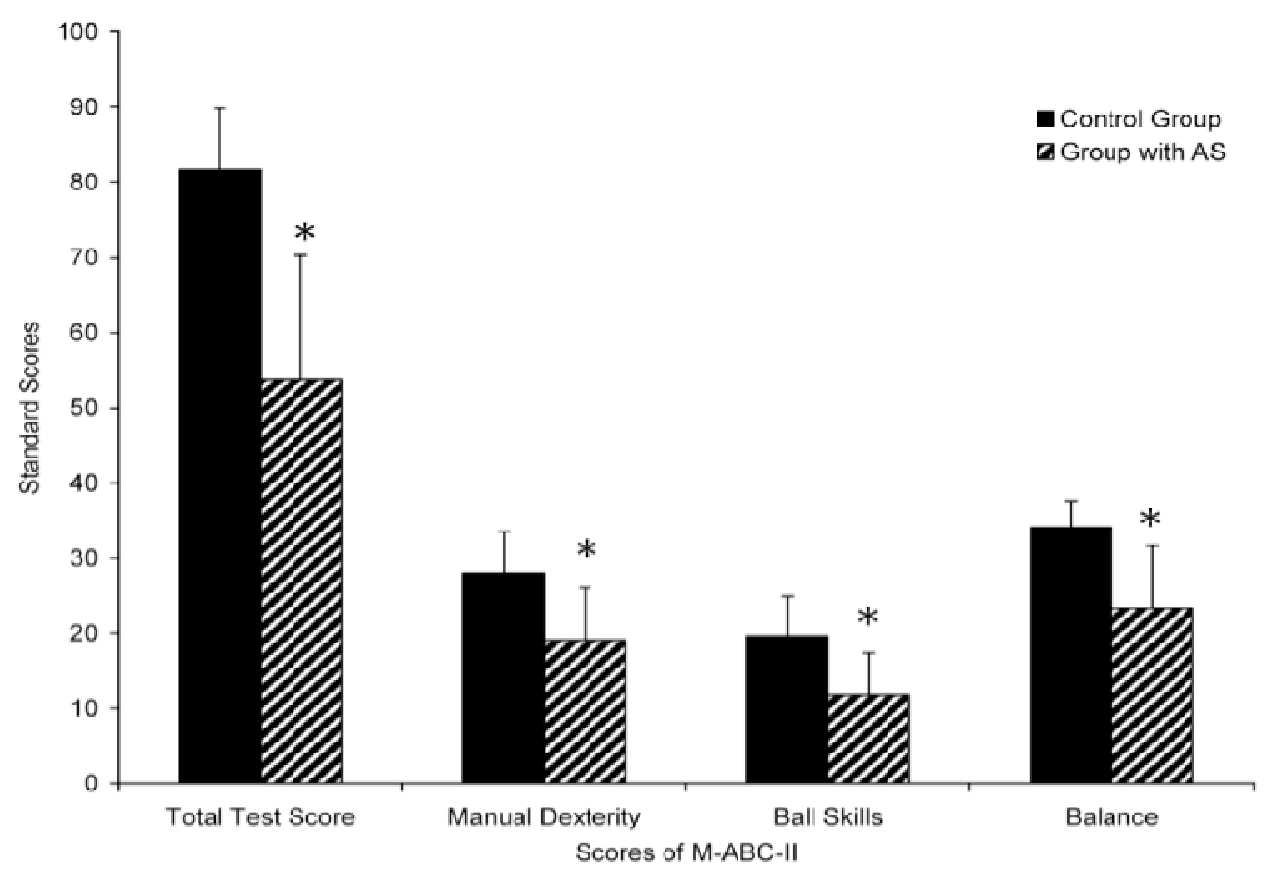

Note. Level of significance $* \mathrm{p}<0.001$.

Figure 2. Percentile equivalents for M-ABC-II total test score for group with AS ( $\mathrm{N}=30)$.

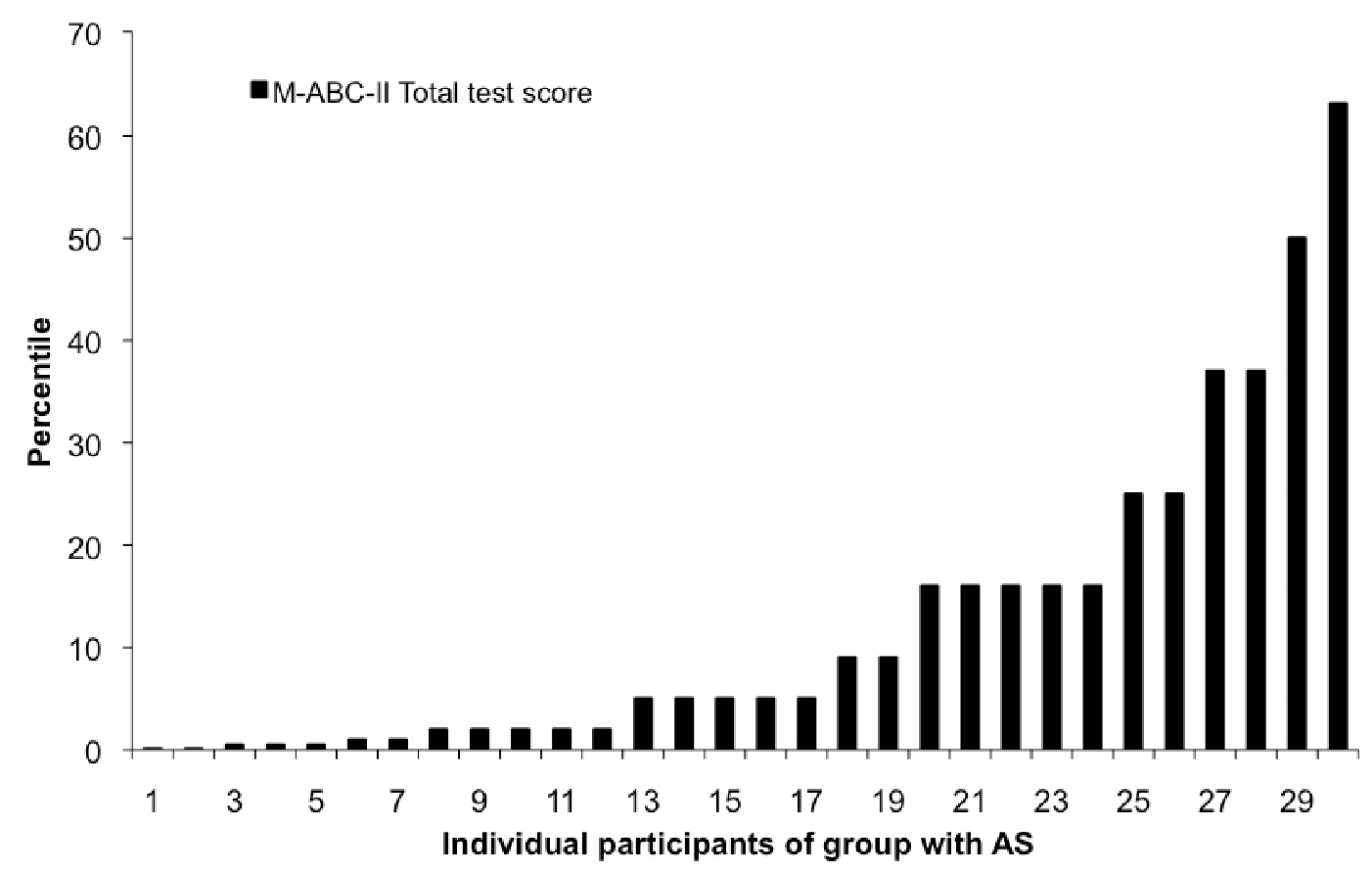


Secondly, the results of the MANOVA on the two groups split by age showed no differences between the youngest and the oldest fifteen in the control group with Wilk's Lambda $\lambda=.56, F(9,20)=1.75$, and $\mathrm{p}>.05$. In the group with AS, the older group scored close to 'significantly different' on the overall motor competence with Wilk's Lambda $\lambda=$ $.56, F(9,20)=4.48$, and exact $\mathrm{p}=.051$. This older group scored significantly better only on the component of manual dexterity with Wilk's Lambda $\lambda=.52, F(4,25)=5.72$, and $\mathrm{p}<.01$. Whereas the differences between the younger and the older group with AS on the components ball skills (with Wilk's Lambda $\lambda$ $=.86, F(3,26)=1.40$, and $\mathrm{p}>.05)$ and balance (with Wilk's Lambda $\lambda=.81, F(4,25)$
$=1.44$ and $\mathrm{p}>.05$ ) were not statistically significant, the data showed relative improvement in both (see Figure 3). The older group scored better on all test items but one, with effect size ranging from $d=0.1$ to $d=$ 1.05. The average effect sizes between the younger and older group with AS on items of the two other components (which were not found to differ significantly) were for ball skill items $\mathrm{d}=.38$ and for balance $\mathrm{d}=.47$. These effect sizes mean that the score of the average person in the older group is respectively .38 and .47 standard deviation above the average person in the group with the fifteen youngest, and hence exceeds the scores of respectively $62 \%$ and $66 \%$ of the youngest fifteen.

Figure 3. Mean component- and total test scores of the M-ABC-II for both younger $(\mathrm{n}=15)$ and older group $(n=15)$ within the group with AS and the control group.

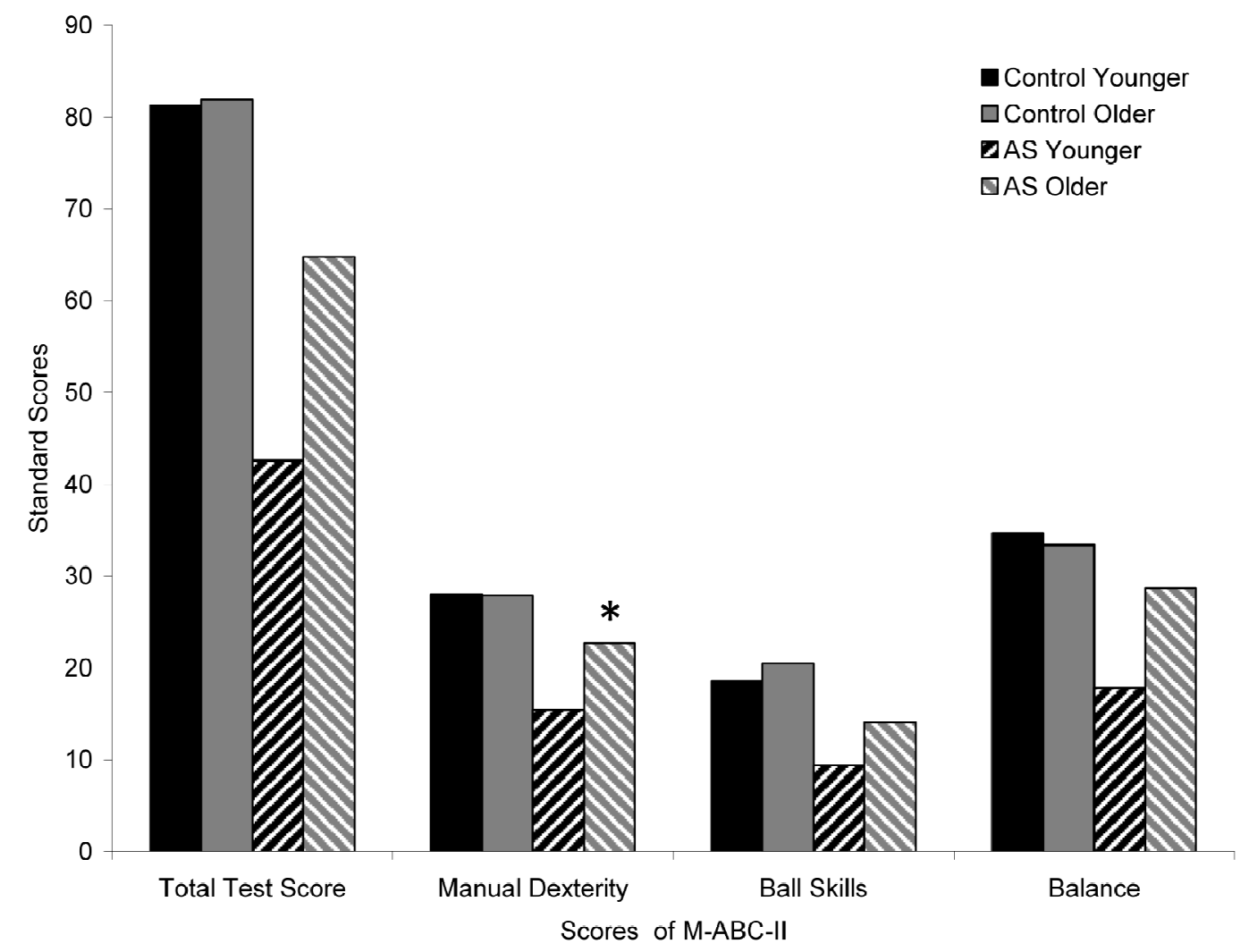

Note. Level of significance $* \mathrm{p}<0.01$ 
The third goal was to provide useful data and indicators for the use of the M-ABC-II measure with our specific AS group of $16+$. For the four-item component of manual dexterity, Cronbach's alpha was low, but equal in both groups with $\alpha=.44$. Results showed that the bimanual task to make a triangle with nuts and bolts was covering a different underlying aspect than the other three items. If this test item would be deleted Crohnbach's alpha reaches acceptable levels of internal consistency, respectively with $\alpha=.65$ for control group and $\alpha=.71$ for the group with AS.

The three-item component of ball skills showed a normal Cronbach's alpha for the control group with $\alpha=.73$ and a higher value with $\alpha=.84$ for the AS group. The overlap of catch preferred hand and catch non-preferred hand is considerable, and within the AS group the use of both items simultaneously adds no statistical or discriminative power, nor any supplemental variance.

The four item component of balance shows a lower than acceptable Cronbach's alpha in the control group with $\alpha=.35$. This may be an indication that the original test is used beyond limits in this age group due to a ceiling effect. Surprisingly, the Cronbach's alpha is much higher, yet still lower than acceptable, in the group with AS with $\alpha=.57$ meaning that this test has preserved some relevance and consistency in the index group. When both zigzag hopping items are left out, the Cronbach's alpha rises to a recommended level with $\alpha=.73$.

\section{DISCUSSION}

The general discussion of this article covers three main aspects, beginning with the comparison of motor competencies of young adults with AS and age and gender matched controls. Young adults with AS continue to demonstrate motor problems and perform at a much lower level than their peers. Moreover, individuals who were assessed as having severe motor impairment were not likely to have single, isolated motor problems. Generally the individuals with $\mathrm{AS}$ needed either more time to complete the M-ABC-II tasks or performed the tasks less successfully. The nature of these problems seems to be a generalized pervasive motor problem affecting both fine and gross motor abilities. These comparative data should be interpreted with care as the present findings reported relatively low internal consistency levels.

In this field study, based upon test scores and clinical impressions a profile of an individual's performance over the different components of the test was examined and all participants received feedback about their specific strengths and weaknesses in order to design an appropriate intervention. Qualitative and quantitative information gathered using the M-ABC-II item specific observations is provided below to highlight some interesting

insights in the underlying challenges concerning motor skills in individuals with AS.

In the manual dexterity tasks an overall observation was a poor sitting posture with tendency for individuals to hold their head often too close to the task. On the turning pegs task four individuals dropped several pegs on the floor during the trial. Often they tried to rush through the task using jerky movements and excessive force with lack of accuracy as a result. The task with the triangle was often perceived as a challenge. Holding the bolt with one hand and screwing the nut on with the other was the most challenging part in this bimanual task. About $30 \%$ of the students got muddled in the construction sequence and two out of three needed a second trial to finish the task successfully at their own pace. During the paper-pencil drawing trail task about $50 \%$ of the students had difficulties with adequate force control often using excessive force and pressing the pen very hard on the paper. About $30 \%$ of the participants finished the drawing trail successfully without any error. While many students struggled there was large variability within the group with $\mathrm{AS}$, with some individuals being extremely skilled in some fine motor activities, finishing the fastest of the whole study group including the controls. Typically these individuals had enhanced hand-eye coordination, as a result of their specific hobbies, such as knitting and 
building model airplanes, which both involve precise motor skill repetition.

The students' 'aiming and catching' accuracy appeared to be particularly poor. When catching a tennis ball with one hand the movements often lacked fluency and participants had difficulty judging the accurate force of the throw. There was a tendency to not anticipate the trajectory of the ball resulting in their hand not 'giving' to meet its impact, thus gradually absorbing the ball's force. Body and arms were held rigidly, making it a challenge to move quickly to the left or to the right, forward or back, to intercept the ball. Often timing was an issue too, with their fingers closing a fraction too late. In average they could catch every second ball. Some students had difficulty changing their hand positions in preparation of a catch. They had difficulty depending on where the ball is, to execute the right movement pattern, meaning pointing the fingers up when catching a high ball and down when catching a low one. At the end of the formal testing students were allowed to catch with both hands and also use their body in their attempt to catch successfully. Throwing at the wall target was easier, with on average every second ball hitting the target. When some participants started off unsuccessfully with one hand they changed hands during the trial with variable force control.

On the balance tasks $25 \%$ of the students could stand for 30 seconds on the boards. The ones who could not balance often showed exaggerated movements of both arms and trunk to stay in balance. In the walking toe-to-heel test it was very difficult for some participants to keep both legs on the line at the start. The ones who were not so successful often went too fast for accuracy, in an attempt to overcome wobbliness when placing their feet on the line. In the zigzag hopping most students were successful after the second attempt with some having problems stopping at the end causing stumbling on landing.

The confirmatory calculation of percentiles based each individuals' raw scores indicated the severity of the motor impairment (See Figure 2). Our results suggest that $63 \%$ are at risk for motor impairment. Most of the 19 individuals with $\mathrm{AS}$ who scored below the $15^{\text {th }}$ percentile displayed a range of motor problems across the three subscales of the M-ABC-II, often with ball skills being the most affected. Another five individuals scored on the $16^{\text {th }}$ percentile. These individuals were more likely to have one or two areas of relative strength, often with one score close to the $50^{\text {th }}$ percentile. While their stronger areas seem to be balance and fine motor skills, ball skills were the lowest and proved the most difficult. In the control group percentile scores ranged form the $16^{\text {th }}$ to the $95^{\text {th }}$ putting all controls participants within normal range. As expected gender differences were minimal in both groups and this is in line with previous research using the M-ABC-II (Henderson et al., 2007). Nonetheless, the summary of these findings does not reflect the complexity of the actual data where a far more variable picture presides. Because these findings were consistent with those of other studies of children with AS (Green et al., 2002; Manjiviona \& Prior, 1995) and also in adults (Freitag, Kleser, Schneider, \& von Gontard, 2007; Sahlander et al., 2008) we can suggest that motor impairment follows children with AS into adulthood. Longitudinal studies using standardized measures are recommended to support this idea.

Secondly, the results of the MANOVA on the two groups split by age showed, as expected, no differences between the younger and the older in the control group. On the contrary the results showed a nearly statistically significant overall motor competence difference between the groups with AS. Despite possible improvement with increasing age, motor impairment continues to be present into young adulthood among individuals with AS. With this small sample size, statistical significance should not misguide us when focusing on effect size. Relative improvements were found in all three components including the two non-significant differing ones, ball skill as well as balance. Due to the small sample size and the unavailability of equal groups at each age level we may have been unable to detect any actual developmental trend difference. Developmental research, with larger sample sizes and multiple 
measures over time, is needed in order to capture the proposed trend in detail.

The third goal was to provide a preliminary exploration of the use of the M-ABC-II in young adults with AS. Our data suggest that the M-ABC-II provides evidence of validity for young adults with $\mathrm{AS}$ as the test is able to distinguish between groups of individuals who might be expected to have movement difficulties (as our index group) and those whose motor development is typical for their age (as our control group). According to our tentative statistical analysis (as Cronbach's alpha) the M-ABC-II test has a rather low degree of validity, with Cronbach's alpha being higher in the group with AS than in the control group. Therefore careful interpretation of the current findings is suggested, as also considerable variability within and between the groups was observed. When in the control group ceiling levels were reached on many of the test items, in the group with AS all test items but one (zigzag hopping) were still challenging enough and able to differentiate between individual's ability. In the present study, based upon statistical analysis, internal consistency would have been at a more acceptable level when for example drawing trail and zigzag hopping would have been omitted. There is a need to further elaborate on the eventual need to omit and/or adapt some of the test items. Future research using the MABC-II with adults should address population specific psychometric properties in order to give a clearer recommendation to fine-tune this test instrument.

Even though establishing age norms for adults is needed, we recommend the use of the M-ABC-II assessment battery with young adults with AS in clinical practice when the test results are interpreted alongside other data, both formally and informally, and classification of individuals as impaired/not impaired is not drawn from a single score from one test. For young adults with AS motor performance may be expected to improve after the age of 16, and it seems that the M-ABC-II test may be sensitive to motor strengths and weaknesses of these individuals.
Further, it must be recognized that the findings of the present study are limited by the use of a single test of motor impairment with mean age of the participants above the age range of the M-ABC-II. While capturing deficits in different areas of motor functioning, it does not provide specific information on the patterns of the impairments, nor on the relationships between other important characteristics of AS such as social interaction and communication. Therefore, studies using multiple tools with larger samples are recommended to further clarify the aspects of motor coordination in individuals with AS. Design limitations notwithstanding, the findings of this study provide meaningful information regarding: the motor profiles of young adults with AS as it replicated problems in fine and gross motor skills previously found in children, and the use of the M-ABC-II with this specific population.

\section{PERSPECTIVE}

The findings of the present study highlight the need for appropriate assessment of motor skills of young adults in adapted physical education. In this study, young adults with AS were assessed using a standardized test intended for a younger population. However, the findings of our study support the feasibility of using the MBC-II for this group, as many participants were identified as being at-risk for severe motor impairment. Because of the limited norm referenced instruments for those above the age of 16 years, professionals working with young adults are often challenged in the selection of appropriate measurement instruments. Even though establishing age norms for adults is certainly a future research objective, we do recommend the 'careful' use of the M-ABC-II for young adults with AS. In our view it is a valuable tool in assessing motor abilities for setting up the intervention in clinical practice.

\section{Acknowledgements}

This research was funded in part by a grant from the Finnish Ministry of Education (OPM, Valtionavustus 2009). The authors would like to thank Sanna Blair and Harriet Valovirta for 
their expert assistance with data collection. We are also very grateful to the staff, parents and last but not least, students for collaborating in this study.

\section{REFERENCES}

American Psychiatric Association (1994). Diagnostic and statistical manual of mental disorders (DSM-IV) (4th ed.). Washington DC: Author.

Attwood, T. (1998). Asperger's syndrome : a guide for parents and professionals. London ; Philadelphia: Jessica Kingsley Publishers.

Baird, G., Simonoff, E., Pickles, A., Chandler, S., Loucas, T., Meldrum, D., et al. (2006). Prevalence of disorders of the autism spectrum in a population cohort of children in South Thames: the Special Needs and Autism Project (SNAP). Lancet, 368(9531), 210215.

Chow, S. M., \& Henderson, S. E. (2003). Interrater and test-retest reliability of the Movement Assessment Battery for Chinese preschool children. American Journal of Occupational Therapy, 57(5), 574-577.

Cohen, J. (1988). Statistical power analysis for the behavioral sciences (2nd ed.). Hillsdale, NJ: Lawrence Earlbaum Associates.

Ehlers, S., Gillberg, C., \& Wing, L. (1999). A screening questionnaire for Asperger syndrome and other high-functioning autism spectrum disorders in school age children. Journal of Autism and Developmental Disorders, 29(2), 129-141.

Faber, I. R., \& Nijhuis van der Sanden, M. W. G. (2004). The Movement Assessment Battery for Children. Standardisation and reliability of Age Band 5: young adults. In L. Henderson, D. Sugden \& A. Barnett (Eds.), The Movement Assessment Battery for Children-2. (2007 ed.). London: Pearson Assessment.

Fombonne, E. (2003). Epidemiological surveys of autism and other pervasive developmental disorders: an update. Journal of Autism and Developmental Disorders, 33(4), 365-382.

Freitag, C. M., Kleser, C., Schneider, M., \& von Gontard, A. (2007). Quantitative assessment of neuromotor function in adolescents with high functioning autism and
Asperger syndrome. Journal of Autism and Developmental Disorders, 37(5), 948-959.

Ghaziuddin, M., \& Butler, E. (1998). Clumsiness in autism and Asperger syndrome: a further report. Journal of Intellectual Disability Research, 42(1), 4348.

Ghaziuddin, M., Butler, E., Tsai, L., \& Ghaziuddin, N. (1994). Is clumsiness a marker for Asperger syndrome? Journal of Intellectual Disability Research, 38(5), 519527.

Gillberg, I. C., \& Gillberg, C. (1989). Asperger syndrome - some epidemiological considerations: a research note. Journal of Child Psychology and Psychiatry and Allied Disciplines, 30(4), 631-638.

Green, D., Baird, G., Barnett, A. L., Henderson, L., Huber, J., \& Henderson, S. E. (2002). The severity and nature of motor impairment in Asperger's syndrome: a comparison with specific developmental disorder of motor function. Journal of Child Psychology and Psychiatry and Allied Disciplines, 43(5), 655-668.

Henderson, S., Sugden, D., \& Barnett, A. L. (2007). Movement Assessment Battery for Children-2. London: Pearson Assessment.

Klin, A., Volkmar, F. R., Sparrow, S. S., Cicchetti, D. V., \& Rourke, B. P. (1995). Validity and neuropsychological characterization of Asperger syndrome: convergence with nonverbal learning disabilities syndrome. Journal of Child Psychology and Psychiatry and Allied Disciplines, 36(7), 1127-1140.

Largo, R., Fischer, J., \& Caflisch, J. (2002). Zurcher Neuromotorik. Zurich: AWE-Verlag.

Lopata, C., Hamm, E. M., Volker, M. A., \& Sowinski, J. E. (2007). Motor and visuomotor skills of children with Asperger's disorder: preliminary findings. Perceptual and Motor Skills, 104(2), 1183-1192.

Manjiviona, J., \& Prior, M. (1995). Comparison of Asperger syndrome and highfunctioning autistic children on a test of motor impairment. Journal of Autism and Developmental Disorders, 25(1), 23-39.

Mattila, M. L., Kielinen, M., Jussila, K., Linna, S. L., Bloigu, R., Ebeling, H., et al. (2007). 
An epidemiological and diagnostic study of Asperger syndrome according to four sets of diagnostic criteria. Journal of the American Academy of Child and Adolescent Psychiatry, 46(5), 636-646.

Miyahara, M., Tsujii, M., Hori, M., Nakanishi, K., Kageyama, H., \& Sugiyama, T. (1997). Brief report: motor incoordination in children with Asperger syndrome and learning disabilities. Journal of Autism and Developmental Disorders, 27(5), 595-603.

Posserud, M., Lundervold, A. J., \& Gillberg, C. (2006). Autistic features in a total population of 7 to 9-year-old children assessed by the ASSQ (Autism Spectrum Screening Questionnaire). Journal of Child Psychology and Psychiatry, 47(2), 167-175.

Sahlander, C., Mattsson, M., \& Bejerot, S. (2008). Motor function in adults with Asperger's disorder: a comparative study. Physiotherapy Theory and Practice, 24(2), 73-81.
Siaperas, P., Holland, T., \& Ring, H. (2006). Discriminative validity of the Movement ABC Test and Checklist for use with children with Asperger Syndrome. In S. E. Henderson, D. Sugden \& A. Barnett (Eds.), Movement Assessment Battery for Children-2 (2007 ed.). London: Pearson Assessment.

Smith, I. M. (2000). Motor functioning in Asperger syndrome. In A. E. Klin (Ed.), Asperger syndrome (pp. 97-124). New York: The Guilford Press. .

World Health Organisation (1993). International statistical classification of diseases and health-related problems, Tenth Revision (ICD-10). Geneva: Author.

Corresponding author's e-mail address: erwin.borremans@gmail.com

\section{MOTORISCHE FERTIGKEITEN VON JUNGEN ERWACHSENEN MIT ASPERGER SYNDROM: EINE VERGLEICHSSTUDIE}

(Resümee)

Störungen der motorischen Fertigkeiten werden als übliches Charakteristikum des Asperger Syndroms (AS) beschrieben, allerdings sind spezifische Informationen in Hinblick auf junge Erwachsene spärlich. Die Absicht dieser Studie war: ein Vergleich der motorischen Fertigkeiten junger Erwachsener mit AS zu einer in Alter und Geschlecht passenden Kontrollgruppe unter Verwendung einer aktualisierten Version der standardisierten Movement Assessment Battery for Children (M-ABC-II) sowie ein Vergleich der Leistungen zwischen jüngeren und älteren Teilnehmern innerhalb beider Gruppen (Versuchs- und Kontrollgruppe). Zusätzlich wurden Validität und Reliabilität der M-ABC-II für die Anwendung in der betreffenden Zielgruppe überprüft. Junge Erwachsene mit AS erbrachten die motorischen Aufgaben auf einem bemerkenswert niedrigeren Niveau als ihre Peers. Sie zeigten fortgesetzte motorische Entwicklungsverzögerungen im Altersgang, wenn es auch schien, als ob sich die motorischen Fähigkeiten der Jugendlichen mit AS nach den Entwicklungsjahren verbesserten. Die Verwendung der M-ABC-II kann für junge Erwachsene mit AS als nützliches Mittel zur Erhebung motorischer Fertigkeiten bei Interventionen in der erzieherischen und klinischen Praxis empfohlen werden.

SCHLÜSSELWÖRTER: Asperger Syndrom, motorische Fertigkeiten, motorische Fähigkeiten, Ungeschicklichkeit, M-ABC-II, Erwachsene. 


\section{COMPETENCES MOTRICES DE JEUNES ADULTES ATTEINTS DU SYNDROME D'ASPERGER MOTOR : UNE ETUDE COMPARATIVE \\ (Résumé)}

Les difficultés liées aux compétences motrices sont décrites comme un trait commun de syndrome d'Asperger (AS), mais des informations spécifiques concernant les jeunes adultes sont rares. Les objectifs de cette étude étaient les suivants: comparer les compétences motrices de jeunes adultes avec AS avec des groupes contrôles appariés selon l'âge et le sexe, en utilisant la version mise à jour du test d'évaluation «Movement Assessment battery for children" (M-ABC-II), et de comparer les compétences motrices entre les participants les plus jeunes et les plus âgés au sein des deux groupes (groupe expérimental et groupe témoin). En outre, la validité et la fiabilité du test d'évaluation M-ABC-II pour son utilisation avec la population ont été étudiées. Les jeunes adultes avec AS ont effectué ces tâches motrices à un niveau nettement inférieur à celui de leurs pairs. Ils ont démontré que les retards moteurs perdurent avec l'avancée en âge, même si les compétences motrices des personnes atteintes d'AS semblaient s'améliorer après l'adolescence. L'utilisation du test $\mathrm{M}$-ABC-II est recommandée pour les jeunes adultes avec AS comme un outil précieux dans l'évaluation des capacités motrices permettant la mise en place d'interventions dans le cadre éducatif et des pratiques cliniques.

MOTS CLEFS : Syndrome d'Asperger, habiletés motrices, compétence motrice, maladresse, MABC-II, adultes. 